\author{
J. Lin - A. Bierhaus $\cdot$ P. Bugert $\cdot$ N. Dietrich $\cdot$ \\ Y. Feng $\cdot$ F. vom Hagen $\cdot$ P. Nawroth $\cdot$ \\ M. Brownlee $\cdot$ H.-P. Hammes
}

\title{
Effect of $R-(+)$-a-lipoic acid on experimental diabetic retinopathy
}

Received: 2 June 2005 / Accepted: 12 December 2005 / Published online: 7 March 2006

C) Springer-Verlag 2006

\begin{abstract}
Aims/hypothesis: Hyperglycaemia-induced mitochondrial overproduction of reactive oxygen species (ROS) is central to the pathogenesis of endothelial damage in diabetes. $\mathrm{R}-(+)-\alpha$-lipoic acid has advantages over classic antioxidants, as it distributes to the mitochondria, is regenerated by glycolytic flux, and has a low redox potential. Methods: To assess the effect of R$(+)-\alpha$-lipoic acid on experimental diabetic retinopathy, three groups of male Wistar rats were studied: nondiabetic controls, untreated diabetic controls, and diabetic rats treated with $60 \mathrm{mg} / \mathrm{kg}$ bodyweight $\mathrm{R}-(+)-\alpha$-lipoic acid i.p. for 30 weeks. Quantitative retinal morphometry included acellular occluded capillaries and pericyte numbers. The effects of R-(+)- $\alpha$-lipoic acid on parameters of oxidative and nitrative stress, $\mathrm{AGE}$ and its receptor and nuclear factor kappa $\mathrm{B}(\mathrm{NFKB})$ were assessed by immunoblotting, and NFKB activation by electrophoretic mobility shift assay. Angiopoietin-2 and vascular endothelial growth factors were also determined
\end{abstract}

J. Lin · P. Bugert · N. Dietrich · Y. Feng ·

F. vom Hagen - H.-P. Hammes

5th Medical Clinic, University-Clinic Mannheim,

Medical Faculty of the University of Heidelberg,

Heidelberg, Germany

A. Bierhaus $\cdot$ P. Nawroth

Department of Internal Medicine I,

University of Heidelberg,

Heidelberg, Germany

M. Brownlee

Diabetes Research Center, Departments of Medicine and Pathology, Albert Einstein College of Medicine, New York, NY, USA

H.-P. Hammes $(\square)$

5th Medical Department, Klinikum Mannheim,

University of Heidelberg,

Theodor-Kutzer-Ufer 1-3,

D-68167 Mannheim, Germany

e-mail: hans-peter.hammes@med5.ma.uni-heidelberg.de

Tel.: +49-621-3832663

Fax: +49-621-3832663 by immunoblotting. Results: After 30 weeks of diabetes, the number of acellular capillaries was significantly elevated in diabetic rats $(57.1 \pm 10.6$ acellular capillary segments $[\mathrm{ac}] / \mathrm{mm}^{2}$ of retinal area) compared with nondiabetic $\left(19.8 \pm 5.1 \mathrm{ac} / \mathrm{mm}^{2} ; p<0.001\right)$. Treatment with $60 \mathrm{mg} / \mathrm{kg} \mathrm{R}-(+)-\alpha$-lipoic acid reduced the numbers by $88 \%(p<0.001$ vs diabetic). Pericyte loss was also significantly inhibited in diabetic rats treated with R- $(+)-\alpha-$ lipoic acid (non-diabetic: $1,940 \pm 137$ pericytes $/ \mathrm{mm}^{2}$ capillary area; untreated diabetic: $1,294 \pm 94$ pericytes $/ \mathrm{mm}^{2}$ capillary area vs treated diabetic: $1,656 \pm 134$ pericytes $/ \mathrm{mm}^{2}$; $p<0.01)$. R-( + - $\alpha$-lipoic acid treatment reduced oxidative stress, normalised NFKB activation and angiopoietin-2 expression, and reduced vascular endothelial growth factor in the diabetic retina by $43 \%(p<0.0001)$. Conclusions/ interpretation: $\mathrm{R}-(+)-\alpha$-lipoic acid prevents microvascular damage through normalised pathways downstream of mitochondrial overproduction of ROS, and preserves pericyte coverage of retinal capillaries, which may provide additional endothelial protection.

Keywords Endothelium - Microvascular disease · Oxidative stress $\cdot$ Rat $\cdot$ Retinopathy

Abbreviations ac: acellular capillary segments . Ang-2: angiopoietin-2 C CML: $N^{\varepsilon}$-carboxymethyllysine DTT: dithiothreitol - GAPDH: glyceraldehyde-3-phosphate dehydrogenase $\cdot \mathrm{NF} \kappa \mathrm{B}$ : nuclear factor kappa B . O-GlcNAc: $O$-linked $N$-acetylglucosamine $\cdot$ RAGE: receptor for AGE - ROS: reactive oxygen species . STZ: streptozotocin - VEGF: vascular endothelial growth factor

\section{Introduction}

Large clinical studies have demonstrated the crucial contribution of chronic hyperglycaemia to the development of diabetic retinopathy $[1,2]$. The pathobiological link between hyperglycaemia and retinal capillary damage is known as the 'unifying hypothesis'. This concept proposes 
that high glucose in endothelial cells is turned into mitochondrial overproduction of reactive oxygen species (ROS), which inactivate glyceraldehyde-3-phosphate dehydrogenase (GAPDH) by activation of poly-ADP-ribose polymerase and subsequent ADP-ribosylation [3, 4]. Endothelial cells, but not smooth muscle cells exposed to high ambient glucose are unable to counterbalance increased transcellular glucose transport, which explains the differential susceptibility to hyperglycaemic injury [5]. The metabolic block at the level of inhibited GAPDH activity directs the substrate flux into known pathways of hyperglycaemic damage. Several therapeutic options emerge: one is to shift substrates into the non-toxic pentose-phosphate shuttle by activating transketolase $[6,7]$. Another is the use of antioxidants. There is evidence for increased oxidative stress in the diabetic retina [8-10]. However, classic antioxidants are unsuitable, because they act stoichiometrically. Several experimental and clinical trials have shown that antioxidants fail to protect from diabetic vascular damage [11-13]. $\mathrm{R}-(+)-\alpha$-lipoic acid is an exception, because it differs from other available antioxidants in three important aspects: (1) it distributes to mitochondria; (2) it has a very low redox potential, recycling other cellular antioxidant redox pairs (such as ascorbate); and (3) it is regenerated by hyperglycaemia- and NEFA-induced NADH (via pyruvate dehydrogenase), linking the antioxidant activity to the degree of increased metabolic flux [14-16].

On the cell biology level, growth/survival factors determine important retinal capillary changes in response to oxidative stress, such as pericyte loss and the formation of acellular capillaries. Vascular endothelial growth factor (VEGF), which is an important player in proliferative diabetic retinopathy, is transcriptionally increased by chronically elevated glucose, and by AGE $[17,18]$. However, VEGF, like other growth factors, not only acts as a proliferative, but also as a survival factor, and recent studies using conditional VEGF knock-out mice have phenocopied early diabetic retinopathy in non-diabetic mice [19]. Pericytes, which are known to protect capillaries from regression, are lost from the very beginning of retinopathy. One possibility is the induction of cell death via the receptor for AGE (RAGE)-nuclear factor kappa B (NFKB) pathway [20, 21]; another is the active elimination of pericytes from the endothelium by factors such as angiopoietin-2 (Ang-2) [22]. Therefore, our aim was to assess qualitatively and quantitatively the impact of R-(+)- $\alpha$-lipoic acid on biochemical and cell biological parameters which are abnormal in the diabetic retina, and on major structural parameters of experimental diabetic retinopathy.

\section{Materials and methods}

Experiments performed in this study complied with the requirements of the Association for Research in Vision and Ophthalmology statement for the 'Use of Animals in Ophthalmic and Vision Research'.
Animals

Six-week-old male Wistar rats (Charles River, Sulzfeld, Germany) were rendered diabetic by i.v. injection of $65 \mathrm{mg} / \mathrm{kg}$ body weight streptozotocin (STZ) (Roche, Mannheim, Germany). Glucose levels and body weight were monitored consecutively throughout the study, and $\mathrm{HbA}_{1 \mathrm{c}}$ was determined at the end of the study by affinity chromatography (Glyc Affin; Isolab, Akron, OH, USA). Rats were categorised as diabetic when blood glucose exceeded $15 \mathrm{mmol} / \mathrm{l}$ at 1 week after STZ injection. Diabetic rats $(n=16)$ were randomly assigned to receive $60 \mathrm{mg} / \mathrm{kg}$ body weight $\mathrm{R}-(+)-\alpha$-lipoic acid i.p. for 5 days per week for 30 weeks or no treatment. Age-matched rats which had not received STZ served as controls.

At the end of the experiments, eyes were obtained from deeply anaesthetised animals. The right eyes were assigned to retinal digest preparation, and the left eyes were used for extraction procedures.

\section{Immunoblotting and assessment of NFKB activity}

Retinal protein was extracted from freshly enucleated eyes ( $n=4$ from diabetic groups, and $n=3$ from the control group) and processed as described [17]. For that purpose, isolated individual retinae were homogenised in a lysis buffer (containing $63 \mathrm{mmol} / \mathrm{l}$ Tris- $\mathrm{HCl}, \mathrm{pH} 6.8 ; 1 \%$ Nonidet P-40; $0.25 \% \mathrm{SDS} ; 150 \mathrm{mmol} / 1 \mathrm{NaCl} ; 1 \mathrm{mmol} / \mathrm{l} \mathrm{EDTA} ; 5 \mathrm{mmol} / \mathrm{l}$ EGTA; $1 \mathrm{mmol} / \mathrm{l}$ phenylmethylsulphonyl fluoride; $1 \mu \mathrm{g} / \mathrm{ml}$ of aprotinin and leupeptin; $2 \mathrm{mmol} / 1$ benzamidine; $1 \mathrm{mmol} / 1$ $\mathrm{NaF} ; 10 \mathrm{nM}$ okadaic acid; and $0.1 \%$ SDS). Protein concentrations were determined using a standard protocol for protein assay (Bio-Rad, Munich, Germany). Samples (15 $\mu \mathrm{g}$ per retinal extract) were run on 4-15\% SDS-PAGE gel electrophoresis, blocked with $10 \%$ non-fat milk in PBS, and membranes incubated with antibodies against methylglyoxal-derived imidazole-type AGE, RAGE, NFkB p 65, $N^{\varepsilon}$-carboxymethyllysine (CML), VEGF and Ang-2 as described $[6,17,22]$. $O$-linked $N$-acetylglucosamine $(O$ GlcNAc) glycosylated proteins were determined using a monoclonal antibody against $O$-GlcNAc residues attached to serine or threonine residues of retinal proteins. Immune complexes were visualised with an anti-mouse horseradish peroxidase-conjugated secondary antibody (1:3,000; DAKO, Hamburg, Germany), and membranes were developed using the ECL system (Amersham, Freiburg, Germany). Membranes were reprobed using a $\beta$-actin antibody (1:1,000; Santa Cruz Biotechnology, Heidelberg, Germany). Immune complex quantification was performed exactly as described [6].

Nitrotyrosine modification of retinal proteins was determined in the retinal extracts using a commercially available test system (Upstate Biochemicals). Oxidised protein detection was performed using a commercial test kit (Chemicon, Hampshire, UK). 
Electrophoretic mobility shift assays were performed as described previously in detail [23]. In brief, frozen retinal tissue from individual retinae ( $n=2$ for non-diabetic, $n=3$ for diabetic and treated diabetic rats) was homogenised under liquid nitrogen using a pestle and transferred to $400 \mu \mathrm{l}$ buffer A $\left(10 \mathrm{mmol} / \mathrm{l} \mathrm{HEPES}-\mathrm{KOH}, \mathrm{pH} 7.9\right.$ at $4^{\circ} \mathrm{C}$; $1.5 \mathrm{mmol} / 1 \mathrm{MgCl}_{2} ; 10 \mathrm{mmol} / 1 \mathrm{KCl} ; 0.5 \mathrm{mmol} / 1$ dithiothreitol [DTT]; $0.2 \mathrm{mmol} / 1$ phenylmethylsulphonyl fluoride; $0.6 \%$ Nonidet-P40). Insoluble material was removed by centrifugation $\left(30 \mathrm{~s}\right.$ at $\left.390 \times \mathrm{g}, 4^{\circ} \mathrm{C}\right)$ and the supernatant was incubated on ice for $15 \mathrm{~min}$ before centrifuged for 5 min at $6,200 \times g, 4^{\circ} \mathrm{C}$. The supernatant was discarded and the nuclear pellet was resuspended in $100 \mu \mathrm{l}$ buffer B $(25 \%$ glycerol; $20 \mathrm{mmol} / 1$ HEPES- $\mathrm{KOH} \mathrm{pH} 7.9$, at $4^{\circ} \mathrm{C}$; $420 \mathrm{mmol} / 1 \mathrm{NaCl} ; 1.5 \mathrm{mmol} / 1 \mathrm{MgCl}_{2} ; 0.2 \mathrm{mM}$ EDTA; $0.5 \mathrm{mmol} / 1 \mathrm{DTT} ; 0.2 \mathrm{mmol} / \mathrm{l}$ phenylmethylsulphonyl fluoride; $2 \mathrm{mmol} / \mathrm{l}$ benzamidine; $5 \mathrm{mg} / \mathrm{ml}$ leupeptin) and incubated on ice for $20 \mathrm{~min}$. Cellular debris was removed by 2 min centrifugation at $4{ }^{\circ} \mathrm{C}$ and the supernatant was quick frozen at $-80^{\circ} \mathrm{C}$. Protein concentrations were determined by a Bradford assay. Ten micrograms of nuclear extract were included in the binding reaction. Binding to an NFKB-consensus oligonucleotide (5'AGTTGAGGGGACTTTCCAGGC-3') was performed in $10 \mathrm{mmol} / \mathrm{l} \mathrm{HEPES}, \mathrm{pH} 7.5,0.5 \mathrm{mmol} / 1$ EDTA, $100 \mathrm{mmol} / 1$ $\mathrm{KCl}, 2 \mathrm{mmol} / \mathrm{l} \mathrm{DTT}, 2 \%$ glycerol, 4\% Ficoll 400, 0.25\% Nonidet-P40, $1 \mathrm{mg} / \mathrm{ml}$ BSA (DNAse-free) and $0.1 \mu \mathrm{g} / \mu \mathrm{l}$ poly $\mathrm{dI} / \mathrm{dC}$ in a total of $20 \mu \mathrm{l}$ as described. Specificity of binding was ascertained by competition with a 160 -fold molar excess of unlabelled consensus oligonucleotides.

\section{Retinal digest preparation}

Retinal vascular preparations were performed using a pepsin-trypsin digestion technique as previously described [6]. Briefly, a combined pepsin (5\% pepsin in $55 \mathrm{~mol} / \mathrm{l}$, hydrochloric acid for $1.5 \mathrm{~h})$ and trypsin $(2.5 \%$ in $0.2 \mathrm{~mol} / 1$ Tris for $15 \mathrm{~min}$ ) digestion was used to isolate the retinal vasculature. Subsequently, the samples were stained with periodic acid Schiff. The total number of pericytes was counted in ten randomly selected fields of the retina using an image analysing system (AnalysisPro; Olympus Opticals Inc., Hamburg, Germany) and their numbers were normalised to the relative capillary density (numbers of cells per $\mathrm{mm}^{2}$ of capillary area).

\section{Statistical analysis}

Results are given as means \pm SD. For statistical analysis, ANOVA and the Bonferroni multiple comparison test were used (Instat; GraphPad, San Diago, CA, USA). A $p$ value of $p<0.05$ was considered significant.
Table 1 Metabolic and physical parameters of the experimental groups at 30 weeks

\begin{tabular}{|c|c|c|c|}
\hline & $\begin{array}{l}\text { Non-diabetic } \\
(n=5)\end{array}$ & $\begin{array}{l}\text { Diabetic } \\
(n=8)\end{array}$ & $\begin{array}{l}\text { Diabetic+Dex } \\
(n=8)\end{array}$ \\
\hline Body weight (g) & $415 \pm 67$ & $305 \pm 45^{*}$ & $296 \pm 28 *$ \\
\hline $\begin{array}{l}\text { Blood glucose } \\
(\mathrm{mmol} / \mathrm{l})\end{array}$ & $5.1 \pm 0.3$ & $31.3 \pm 4.7^{*}$ & $32.7 \pm 1.6^{*}$ \\
\hline $\mathrm{HbA}_{1 \mathrm{c}}(\%)$ & $6.12 \pm 1.81$ & $12.2 \pm 1.35^{*}$ & $11.90 \pm 1.38^{*}$ \\
\hline
\end{tabular}

Dex R-(+)- $\alpha$-lipoic acid

$* p \leq 0.05$ for difference from non-diabetic groups

\section{Results}

STZ-induced diabetes produced stable hyperglycaemia over the study period. $\mathrm{R}-(+)-\alpha$-lipoic acid had no effect on body weight, or the metabolic parameters tested. Table 1 summarises the metabolic data of the experimental groups.

Chronic hyperglycaemia causes increased formation of AGE and, subsequently, the activation of RAGE. We assessed the AGE-RAGE pathway, and the effect of R-(+)- $\alpha-$ lipoic acid in retinae from the experimental groups using quantitative immunoblotting of retinal protein extracts and image analysis. Compared with non-diabetic controls, the level of methylglyoxal-type AGE was elevated 2.4-fold (Fig. 1a,b). R-(+)- $\alpha$-lipoic acid-treated diabetic rats had retinal methylglyoxal-type AGE levels comparable with non-diabetic animals. RAGE, the receptor for AGE, was upregulated 2.4-fold compared with non-diabetic control rats, and completely normalised in R-(+)- $\alpha$-lipoic acidtreated animals (Fig. 1a,b). The downstream signalling of the AGE-RAGE pathway involves activation of NFkB, which, in turn, can induce RAGE expression. Chronic hyperglycaemia increased NF-KB p65 expression and activation in the retinae of the diabetic group, while R- $(+)-\alpha$-lipoic acid completely prevented this activation (Fig. la,b).

We have previously reported that reduction of the hexosamine pathway activation is part of the beneficial effects observed in successful treatment of experimental diabetic retinopathy [6]. We measured the retinal protein modification by $O$-GlcNAc using protein extracts. In normal retinae, protein modification was virtually not detectable. Compared with untreated diabetic retinae, R- $(+)-\alpha$-lipoic acid-treated retinae exhibited a substantial reduction in the protein modification (Fig. 1c).

Next, the capacity of $\mathrm{R}-(+)-\alpha$-lipoic acid to reduce markers of oxidative stress in the retinae of diabetic rats was evaluated. We used retinal nitrotyrosine as an indicator of nitration of tyrosine residues of proteins induced by the breakdown of peroxynitrite. In diabetic retinae, nitrotyrosine-modified proteins were increased twofold, as assessed by Western blotting of retinal protein extracts. This increase was completely prevented in $\mathrm{R}-(+)-\alpha$-lipoic acid-treated diabetic retinae (Fig. 2a,b). 
Fig. 1 Effect of R-(+)- $\alpha$-lipoic acid administration on the AGERAGE-NFKB axis, and on the hexosamine pathway in the three experimental groups. a Representative immunoblots of retinal protein extracts probed against methylglyoxal $(M G)$ type AGE, RAGE and NFkB p65, and an electrophoretic mobility shift assay of retinal cell nuclear extracts showing NFKB activation. $N$ non-diabetic, $D$ diabetic, $D+D e x$ R-(+)- $\alpha$-lipoic acid-treated diabetic, $D C$-cons diabetic controls + excess of cold consensus NFKB oligonucleotide. b-d Densitometric quantification of the immunoblots for MG-type AGE (b), RAGE (c) and NFKB p65 (c). Each bar graph represents the mean $\pm \mathrm{SD}$ of three $\mathrm{N}$ and four $\mathrm{D}$ and $\mathrm{D}+$ Dex individual retinae. e Densitometric quantification of $O$-linked glycosylation of retinal proteins in N, D and D+Dex rats. MG-type AGE: N vs D and $\mathrm{D}$ vs $\mathrm{D}+\mathrm{Dex} p<0.001$; RAGE: $\mathrm{N}$ vs $\mathrm{D}$ and $\mathrm{D}$ vs $\mathrm{D}+\mathrm{Dex}$ $p<0.001 ; \mathrm{NF} \kappa \mathrm{B}$ p 65 : N vs D and $\mathrm{D}$ vs $\mathrm{D}+\operatorname{Dex} p<0.0001$; $O$-GlcNac-P: N vs D and D vs $\mathrm{D}+$ Dex $p<0.0001$. $A U$ arbitrary units of ratio of the individual signal normalised to the actin signal of the respective samples

Fig. 2 Effect of R-(+)- $\alpha$-lipoic acid on parameters of nitrative and oxidative stress in the retina. a Representative immunoblots of retinal proteins extracts probed against nitrotyrosine, oxidised proteins and CML. $N$ non-diabetic, $D$ diabetic, $D+\operatorname{Dex} \mathrm{R}-(+)-\alpha$-lipoic acidtreated diabetic. b-d Densitometric quantification of the immunoblots for nitrotyrosine (b), oxidised proteins (oxyblot) (c) and CML (d). Retinal protein extracts $(n=3$ for non-diabetic, and $n=4$ for both diabetic groups) were analysed in duplicate, and densitometric levels were expressed as means \pm SD. Nitrotyrosine: $\mathrm{N}$ vs $\mathrm{D}$ and $\mathrm{D}$ vs D+Dex $p<0.001$; Oxyblot N vs D $p<0.001$, D vs D+Dex $p<0.01$; CML: N vs D and D vs $\mathrm{D}+$ Dex $p<0.001$. $A U$ arbitrary units of ratio of the individual signal normalised to the actin signal of the respective samples

a

${ }^{\mathbf{a}}$

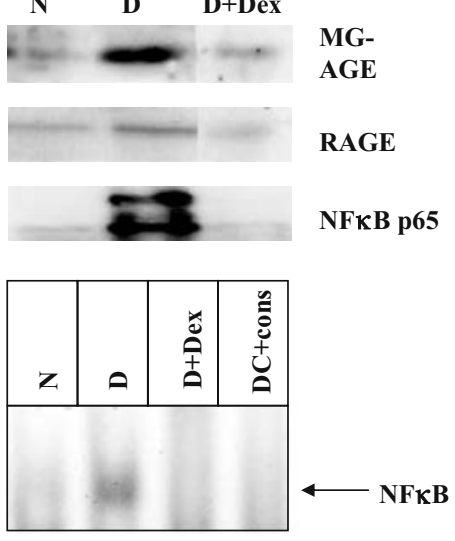

b

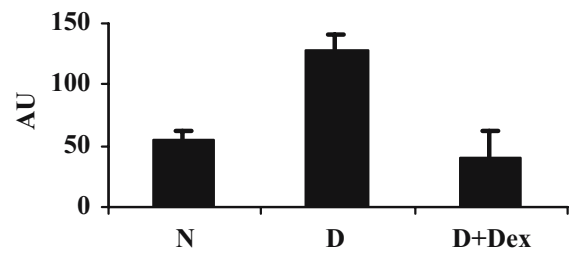

c

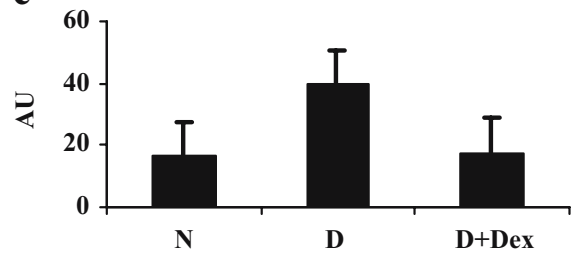

d

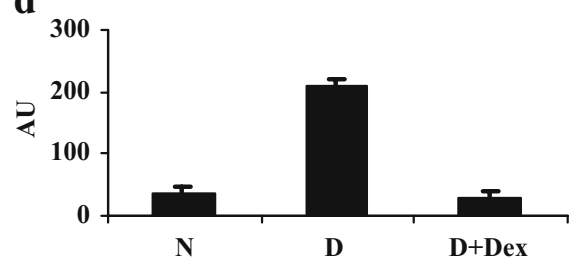

e

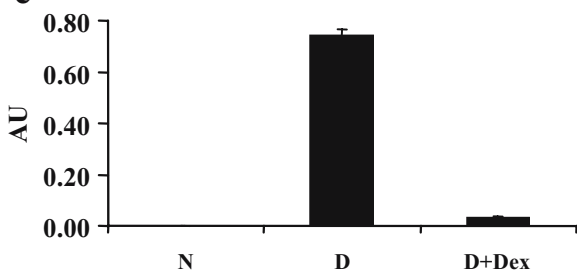

a

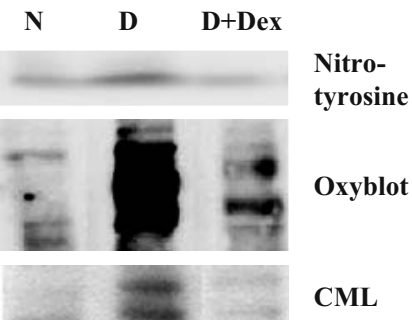

b

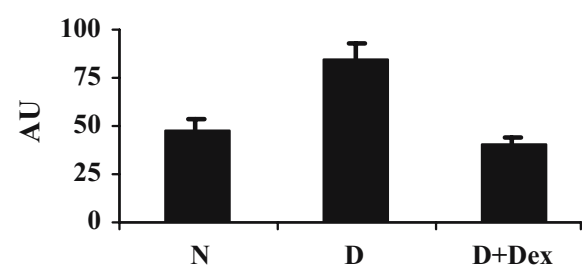

c

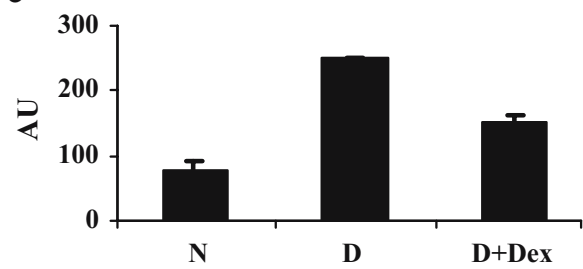

d

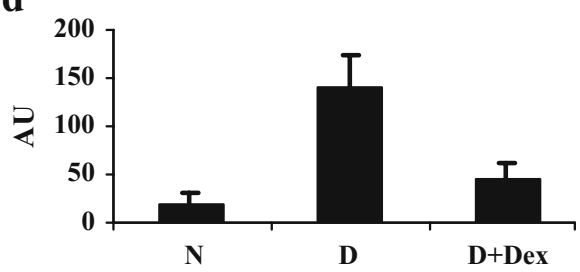


a

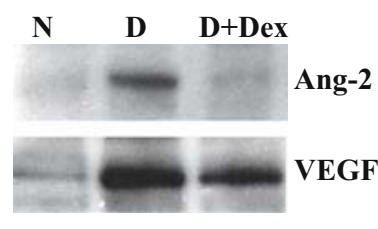

b
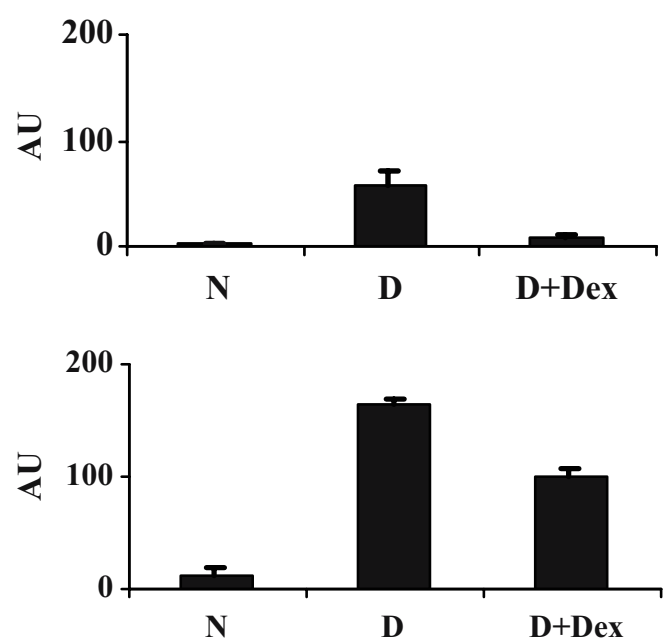

Fig. 3 Effect of R-(+)- $\alpha$-lipoic acid on growth factors in the retina. a Representative immunoblots of retinal protein extracts for Ang-2 and VEGF of the three experimental groups. $N$ non-diabetic, $D$ diabetic, $D+$ Dex R-(+)- $\alpha$-lipoic acid-treated diabetic. b,c Quantification of the immune complexes of Ang-2 and VEGF protein expression, respectively. Retinal protein extracts ( $n=3$ for non- diabetic, and $n=4$ for both diabetic groups) were analysed in duplicate. Individual bars represent mean \pm SD. Ang-2: $N$ vs D and D vs $\mathrm{D}+$ Dex $p<0.0001$; VEGF: $\mathrm{N}$ vs $\mathrm{D} p<0.0001$, D vs $\mathrm{D}+\mathrm{Dex}$ $p<0.01$. $A U$ arbitrary units of ratio of the individual signal normalised to the actin signal of the respective samples
Oxidative stress in diabetic retinae is verified by measuring retinal proteins by derivatisation of carbonyl groups with 2,4-dinitrophenylhydrazine. Using this method, we found a 3.1-fold increase of oxidative protein modifications in diabetic animals, which was reduced by $60 \%$ in the diabetic group treated with $\mathrm{R}-(+)-\alpha$-lipoic acid (Fig. 2a,b).

CML is a marker of oxidation and glycation, and, through its interaction with RAGE, it can propagate prooxidative signals via NFKB. Diabetic retinal extracts had sevenfold more CML-modified proteins than retinal extracts from non-diabetic rats. R- $(+)-\alpha$-lipoic acid treatment inhibited CML modification of proteins by $79.2 \%$ (Fig. 2a,b).

We assessed downstream effectors of cellular response to hyperglycaemic retinal injury. Ang-2 is an important modulator of pericyte recruitment in diabetes. We found detectable Ang-2 protein levels only in diabetic retinae. $\mathrm{R}-(+)-\alpha$-lipoic acid treatment reduced completely this upregulation to levels below detection limits in retinal extracts, when assessed by immunoblotting (Fig. 3a,b).

VEGF is an important survival factor for retinal endothelial (and possibly neuroglial cells) in vivo. We found a major increase of VEGF protein in retinal extracts of diabetic rats. $\mathrm{R}-(+)-\alpha$-lipoic acid treatment of diabetic rats reduced VEGF upregulation by $43 \%$ (Fig. 3a,b).

The formation of acellular capillaries is considered the most important marker of experimental diabetic retinopathy. We analysed retinae of the three experimental groups by quantitative morphometry (Fig. 4a). After 30 weeks of diabetes, retinae of untreated rats had developed threefold more acellular capillaries, compared with control rats $(57.1 \pm 10.6$ acellular capillary segments $[\mathrm{ac}] / \mathrm{mm}^{2}$ of retinal area vs $19.8 \pm 5.1 \mathrm{ac} / \mathrm{mm}^{2}$ of retinal area; $p<0.001$ ) (Fig. $4 \mathrm{~b}$ ). This increase was corrected by $93 \%$ through administration of $\mathrm{R}-(+)$ - $\alpha$-lipoic acid $\left(22 \pm 4 \mathrm{ac} / \mathrm{mm}^{2}\right.$ of retinal area; $p<0.001$ vs diabetic controls). Pericyte dropout in diabetic animals reached almost $34 \%$ after 30 weeks. R-(+)- $\alpha$-lipoic acid treatment reduced it by $56 \%(p<0.01)$ (Fig. $4 \mathrm{~b})$.

\section{Discussion}

We demonstrated that the interference with the sequelae of mitochondrial overproduction of ROS by the catalytic antioxidant R-(+)- $\alpha$-lipoic acid in a model of experimental diabetic retinopathy normalises parameters of oxidative stress in the diabetic retina and prevents the activation of major pathways involved in hyperglycaemia-induced vascular damage. R-(+)- $\alpha$-lipoic acid reduced or even completely normalised downstream effectors of vascular response to injury, and treatment over 30 weeks in diabetic rats inhibited structural vascular damage in the retina, including pericyte dropout.

Our in vivo data show evidence of oxidative protein modification. Earlier short-term studies using DL-alphalipoic acid at similar doses showed inhibition of retinal lipid peroxidation products and superoxide dismutase, but no change in enzymes of glutathione metabolism [4]. In addition, the capacity to reduce mitochondrial ROS overproduction and the concomitant reduction of both intracellular methylglyoxal-type AGE and CML suggests an indirect AGE-inhibiting effect of R-(+)- $\alpha$-lipoic acid.

One important receptor for mediating AGE effects is RAGE [24]. RAGE is expressed in the inner vascularised part of the diabetic retina, both in neuroglial and in vascular cells [25]. Binding of AGE such as CML to RAGE augments and propagates oxidative stress in retinal tissue 
Fig. 4 Effect of R-(+)- $\alpha$-lipoic acid on parameters of experimental diabetic retinopathy. a Photomicrographs of retinal blood vessels isolated from nondiabetic $(N)$, diabetic $(D)$ and $\mathrm{R}-(+)-\alpha$-lipoic acid treated diabetic $(D+D e x)$ rats. Original magnification $200 \times$; * acellular capillaries in diabetic rats. b Quantification of pericyte numbers $/ \mathrm{mm}^{2}$ of capillary area (b) and acellular capillary segments $/ \mathrm{mm}^{2}$ of retinal area (c) in retinal vessels from $\mathrm{N}$ $(n=5), \mathrm{D}(n=8)$, and $\mathrm{D}+\mathrm{Dex}$ rats $(n=8)$. Acellular capillaries: $p<0.001$ for differences observed (each comparison) between the $\mathrm{N}$ and the $\mathrm{D}$, and the $\mathrm{D}$ and the $\mathrm{D}+\mathrm{Dex}$ groups. The differences in pericyte numbers were significant $(p<0.01)$ between the D and the $\mathrm{N}$, and the $\mathrm{D}$ and the $\mathrm{D}+\mathrm{Dex}$ groups a
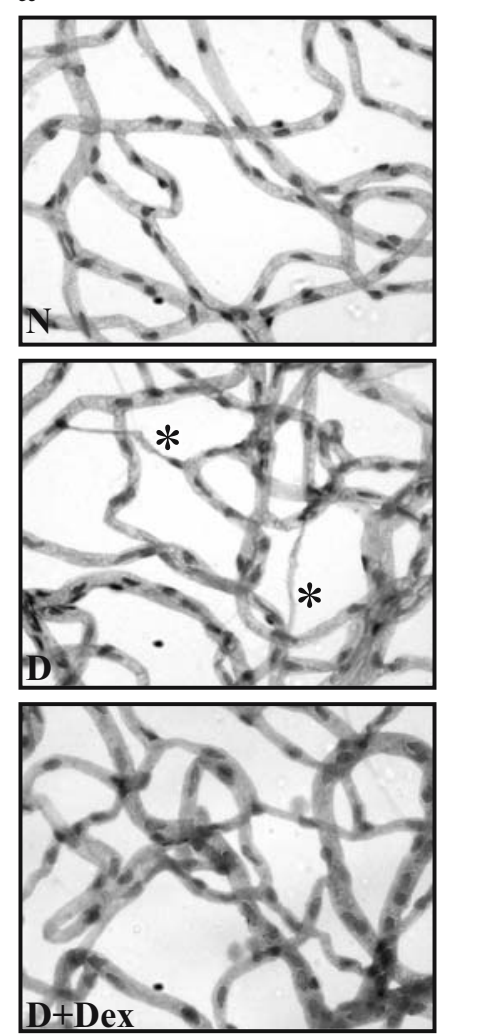

b
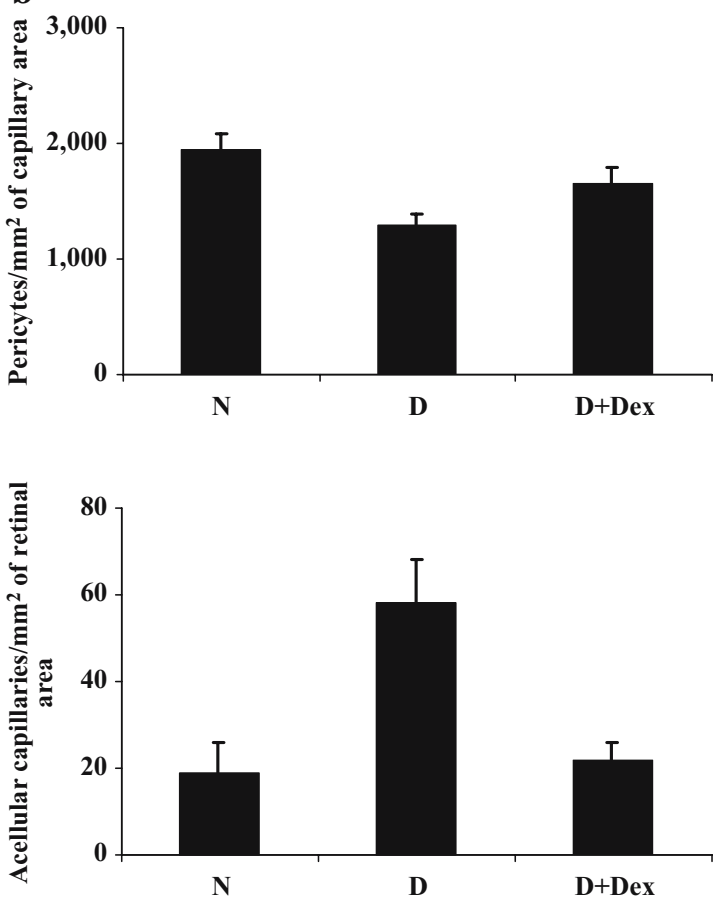

$[25,26]$. RAGE signals via the transcription factor NF $\kappa B$ to activate target genes which have deleterious potential for the diabetic retina $[23,27,28]$. R-(+)- $\alpha$-lipoic acid reduced RAGE expression, NFKB p65 antigen and NFkB binding activity. The pivotal role of RAGE in the mediation of ROS/AGE-induced diabetic microangiopathy is supported by experiments using transgenic and knock-out mice. RAGE-null mice are protected from diabetes-induced retinal damage (H.-P. Hammes, A. Bierhaus et al., unpublished observations). Thus, our data suggest that part of the beneficial effect of $\mathrm{R}-(+)-\alpha$-lipoic acid includes the disruption of the detrimental AGE-RAGE-NFkB axis.

The prevention of pericyte loss by $\mathrm{R}-(+)-\alpha$-lipoic acid treatment is a novel finding. Pericytes exert a survivalpromoting function on retinal capillaries, indicated by the fact that capillaries covered by pericytes are more resistant to regressive signals than capillaries with reduced pericyte coverage [29]. One mechanism by which diabetic pericyte loss can be reduced or even prevented is by the inhibition of Ang-2. Ang-2 is upregulated prior to the onset of pericyte dropout in the diabetic rat, Ang-2 deficiency prevents pericyte dropout, and intravitreal Ang-2 injection induces pericyte dropout in non-diabetic rats [22]. R-(+)- $\alpha$-lipoic acid normalises Ang-2 expression in hyperglycaemia, suggesting a mechanism by which pericyte preservation could be explained, and linking Ang-2 regulation to the overproduction of mitochondrial ROS.
Increased retinal oxidative stress invokes upregulation of VEGF, not only in proliferative diabetic retinopathy, but during incipient diabetic retinopathy, i.e. in the absence of neovascularisation [30-35]. Interestingly, other formulations of $\alpha$-lipoic acid, given for shorter periods, produced complete inhibition of VEGF in the diabetic retina [10]. It remains to be seen whether this discrepancy is due to differences in rat strains, relative concentrations of compounds, or other characteristics. However, our data support the concept that $\mathrm{R}-(+)-\alpha$-lipoic acid interacts with important inducers of VEGF, such as ROS and AGE. R-(+)- $\alpha$-lipoic acid reduces but does not normalise VEGF, in association with an improved survival of endothelial cells in retinal capillaries as reflected by the reduced numbers of acellular capillaries.

Previous studies using oral R- $\alpha$-lipoic acid $(0.05 \% / \mathrm{kg}$ diet), a different rat strain and sex, and a different dose of STZ for diabetes induction, failed to observe the prevention of experimental retinopathy despite some effects on transcription of collagen IV, and a partial inhibition of retinal CML [36]. These data indicate that a threshold dose of R-(+)- $\alpha$-lipoic acid exists under which some biochemical markers may still be modulated, but acellular capillaries are not inhibited.

While this paper was being prepared, Kowluru and Odenbach published data on the racemic mixture of $\alpha$-lipoic acid [37]. They showed that the oral administration of $400 \mathrm{mg} / \mathrm{kg}$ body weight over 11 months in Wistar rats 
reduced retinal oxidative stress and the formation of acellular capillaries. A direct comparison between the isomer and the racemic mixture may be difficult, given the different routes of administration. However, a comparative study in a model of buthionine sulphoximine-induced cataract indicates that $\mathrm{R}-(+)-\alpha$-lipoic acid is selectively taken up by ocular cells [38]. Thus, it cannot be excluded that differences exist between the biological effect of the R-isomer compared with other mixtures of lipoic acid.

In summary, we provide evidence that catalytic reactive oxygen scavenging is an effective approach for the prevention of diabetic retinopathy. $\mathrm{R}-(+)-\alpha$-lipoic acid is a paradigm compound with a broad spectrum of beneficial biochemical and cell biological effects, based on its ability to reduce the sequelae of hyperglycaemia-induced mitochondrial ROS overproduction. Since R-(+)- $\alpha$-lipoic acid also has beneficial effects on other target tissues of diabetic angiopathy, and shows beneficial effects of mediators of large vessel damage, this concept appears attractive for the prevention or delay of diabetic angiopathy.

Acknowledgements The study was supported by the Deutsche Forschungsgemeinschaft (Ha 1755/7-2 to H.-P. Hammes, Y. Feng and N. Dietrich; Na 138/5-3; SFB 405 to P. P. Nawroth.), the Deutsche Diabetes-Gesellschaft (to H.-P. Hammes, J. Lin and A. Bierhaus), the European Foundation for the Study of Diabetes (to F. v. Hagen, H.-P. Hammes and A. Bierhaus) and Viatris Pharma (Frankfurt/Main, Germany) (to H.-P. Hammes).

\section{References}

1. The Diabetes Control and Complications Trial Research Group (1993) The effect of intensive treatment of diabetes on the development and progression of long-term complications in insulin-dependent diabetes mellitus. $N$ Engl J Med 329: 977-986

2. UK Prospective Diabetes Study (UKPDS) Group (1998) Intensive blood-glucose control with sulphonylureas or insulin compared with conventional treatment and risk of complications in patients with type 2 diabetes (UKPDS 33). Lancet 352:837-853

3. Brownlee M (2001) Biochemistry and molecular cell biology of diabetic complications. Nature 414:813-820

4. Du X, Matsumura T, Edelstein D et al (2003) Inhibition of GAPDH activity by poly(ADP-ribose) polymerase activates three major pathways of hyperglycemic damage in endothelial cells. J Clin Invest 112:1049-1057

5. Kaiser N, Sasson S, Feener EP et al (1993) Differential regulation of glucose transport and transporters by glucose in vascular endothelial and smooth muscle cells. Diabetes 42: 80-89

6. Hammes HP, Du X, Edelstein D et al (2003) Benfotiamine blocks three major pathways of hyperglycemic damage and prevents experimental diabetic retinopathy. Nat Med 9:294-299

7. Babaei-Jadidi R, Karachalias N, Ahmed N, Battah S, Thornalley PJ (2003) Prevention of incipient diabetic nephropathy by high-dose thiamine and benfotiamine. Diabetes 52:2110-2120

8. Du Y, Miller CM, Kern TS (2003) Hyperglycaemia increases mitochondrial superoxide in retina and retinal cells. Free Radic Biol Med 35:1491-1499

9. Kowluru RA, Kern TS, Engerman RL, Armstrong D (1996) Abnormalities of retinal metabolism in diabetes or experimental galactosemia. III. Effects of antioxidants. Diabetes 45: 1233-1237
10. Obrosova IG, Minchenko AG, Marinescu V et al (2001) Antioxidants attenuate early up regulation of retinal vascular endothelial growth factor in streptozotocin-diabetic rats. Diabetologia 44:1102-1110

11. Heart Outcomes Prevention Evaluation Study Investigators (2000) Effects of ramipril on cardiovascular and microvascular outcomes in people with diabetes mellitus: results of the HOPE study and MICRO-HOPE substudy. Lancet 355:253-259

12. Mayer-Davis EJ, Bell RA, Reboussin BA, Rushing J, Marshall JA, Hamman RF (1998) Antioxidant nutrient intake and diabetic retinopathy: the San Luis Valley Diabetes Study. Ophthalmology 105:2264-2270

13. Hammes HP, Bartmann A, Engel L, Wülfroth P (1997) Antioxidant treatment of experimental diabetic retinopathy with nicanartine. Diabetologia 40:629-634

14. Liu J, Head E, Gharib AM et al (2002) Memory loss in old rats is associated with brain mitochondrial decay and RNA/DNA oxidation: partial reversal by feeding acetyl-L-carnitine and/or R-alpha-lipoic acid. Proc Natl Acad Sci USA 99:2356-2361

15. Hagen TM, Ingersoll RT, Lykkesfeldt J et al (1999) (R)-alphalipoic acid-supplemented old rats have improved mitochondrial function, decreased oxidative damage, and increased metabolic rate. FASEB J 13:411-418

16. Bustamante J, Lodge JK, Marcocci L, Tritschler HJ, Packer L, Rihn BH (1998) Alpha-lipoic acid in liver metabolism and disease. Free Radic Biol Med 24:1023-1039

17. Hammes HP, Lin J, Bretzel RG, Brownlee M, Breier G (1998) Upregulation of the VEGF/VEGF-receptor system in experimental background diabetic retinopathy of the rat. Diabetes 47:401-406

18. Lu M, Kuroki M, Amano S et al (1998) Advanced glycation end products increase retinal vascular endothelial growth factor expression. J Clin Invest 101:1219-1224

19. Raab S, Beck H, Gaumann A et al (2004) Vascular endothelial growth factor is essential for brain angiogenesis and development. Thromb Haemost 91:595-605

20. Romeo G, Liu WH, Asnaghi V, Kern TS, Lorenzi M (2002) Activation of nuclear factor-kappaB induced by diabetes and high glucose regulates a proapoptotic program in retinal pericytes. Diabetes 51:2241-2248

21. Mizutani M, Kern TS, Lorenzi M (1996) Accelerated death of retinal microvascular cells in human and experimental diabetic retinopathy. J Clin Invest 97:2883-2890

22. Hammes HP, Lin J, Wagner P et al (2004) Diabetes-induced angiopoietin-2 causes pericyte dropout in the normal retina: evidence for involvement in diabetic retinopathy. Diabetes 53:1104-1110

23. Bierhaus A, Schiekofer S, Schwaninger M et al (2001) Diabetes-associated sustained activation of the transcription factor nuclear factor-kappaB. Diabetes 50:2792-2808

24. Stern D, Yan SD, Yan SF, Schmidt AM (2002) Receptor for advanced glycation endproducts: a multiligand receptor magnifying cell stress in diverse pathologic settings. Adv Drug Deliv Rev 54:1615-1625

25. Hammes HP, Alt A, Niwa T, Bretzel RG, Brownlee $M$, Schleicher E (1999) Differential accumulation of advanced glycation end products in the course of diabetic retinopathy. Diabetologia 42:728-736

26. Kislinger T, Fu C, Huber B et al (1999) N(epsilon)(carboxymethyl)lysine adducts of proteins are ligands for receptor for advanced glycation end products that activate cell signaling pathways and modulate gene expression. J Biol Chem 274:31740-31749

27. Schiekofer S, Andrassy M, Chen J et al (2003) Acute hyperglycemia causes intracellular formation of CML and activation of ras, p42/44 MAPK, and nuclear factor kappaB in PBMCs. Diabetes 52:621-633

28. Quehenberger P, Bierhaus A, Fasching P et al (2000) Endothelin 1 transcription is controlled by nuclear factor-kappaB in AGE-stimulated cultured endothelial cells. Diabetes 49: $1561-1570$ 
29. Hammes HP, Lin J, Renner O et al (2002) Pericytes and the pathogenesis of diabetic retinopathy. Diabetes 51:3107-3112

30. Aiello LP, Avery RL, Arrigg PG et al (1994) Vascular endothelial growth factor in ocular fluid of patients with diabetic retinopathy and other retinal disorders. N Engl J Med 331:1480-1487

31. Miller JW, Adamis AP, Shima DT et al (1994) Vascular endothelial growth factor/vascular permeability factor is temporally and spatially correlated with ocular angiogenesis in a primate model. Am J Pathol 145:574-584

32. Murata T, Ishibashi T, Khalil A, Hata Y, Yoshikawa H, Inomata H (1995) Vascular endothelial growth factor plays a role in hyperpermeability of diabetic retinal vessels. Ophthalmic Res 27:48-52

33. Ellis EA, Guberski DL, Somogyi-Mann M, Grant MB (2000) Increased $\mathrm{H}_{2} \mathrm{O}_{2}$, vascular endothelial growth factor and receptors in the retina of the BBZ/Wor diabetic rat. Free Radic Biol Med 28:91-101
34. Gilbert RE, Vranes D, Berka JL et al (1998) Vascular endothelial growth factor and its receptors in control and diabetic rat eyes. Lab Invest 78:1017-1027

35. Sone H, Kawakami Y, Okuda Y et al (1997) Ocular vascular endothelial growth factor levels in diabetic rats are elevated before observable retinal proliferative changes. Diabetologia 40:726-730

36. Stitt A, Gardiner TA, Alderson NL et al (2002) The AGE inhibitor pyridoxamine inhibits development of retinopathy in experimental diabetes. Diabetes 51:2826-2832

37. Kowluru RA, Odenbach S (2004) Effect of long-term administration of alpha-lipoic acid on retinal capillary cell death and the development of retinopathy in diabetic rats. Diabetes 53:3233-3238

38. Maitra I, Serbinova E, Tritschler HJ, Packer L (1996) Stereospecific effects of R-lipoic acid on buthionine sulfoximine-induced cataract formation in newborn rats. Biochem Biophys Res Commun 221:422-429 